\title{
Sludge Removal of Nonsteroidal Anti-Inflammatory Drugs during Wastewater Treatment Studied by Direct Hollow Fiber Liquid Phase Microextraction
}

\author{
Estelle Larsson $^{1 *}$, Ayman Rabayah ${ }^{2}$, Jan $_{\text {Åke Jönsson }}{ }^{1}$ \\ ${ }^{1}$ Lund University, Lund, Sweden; ${ }^{2}$ Triumpharma LLC, Amman, Jordan. \\ Email: *estelle.larsson@chem.lu.se \\ Received May $30^{\text {th }}, 2013$; revised July $2^{\text {nd }}, 2013$; accepted August $1^{\text {st }}, 2013$ \\ Copyright (C) 2013 Estelle Larsson et al. This is an open access article distributed under the Creative Commons Attribution License, \\ which permits unrestricted use, distribution, and reproduction in any medium, provided the original work is properly cited.
}

\begin{abstract}
In this study, the fate of four common anti-inflammatory drugs (ketoprofen, naproxen, diclofenac and ibuprofen) within a wastewater treatment plant was investigated. A previously developed direct hollow fiber liquid phase microextraction method was applied to water as well as sludge samples collected from the primary, secondary and tertiary treatment respectively and the final analysis was performed by liquid chromatography quadropole time of flight tandem mass spectrometry. Enrichment factors ranged from 1400 to 3900 times depending on analyte and matrix. Method detection limits ranged from 0.3 to $14 \mathrm{ng} / \mathrm{L}$ for the different analytes and matrices. The overall sludge removal was $9 \%, 3 \%, 13 \%$ and $1 \%$ for ketoprofen, naproxen, diclofenac and ibuprofen respectively, thus indicating that of the studied compounds, ketoprofen and diclofenac to the largest extent partition into the sludge. For both substances, the largest fraction was found in secondary sludge $(60 \%$ and $80 \%$ respectively of the total amount detected in the sludge). For naproxen and ibuprofen, the largest fraction were on the other hand detected in primary and tertiary sludge respectively, indicating that the affinity to the different sludge types might vary among the four drugs. The overall low sludge removal confirms existing theories that partitioning into sludge is only a minor removal mechanism for the investigated compounds. Nevertheless, naproxen and ibuprofen are still efficiently removed from the water during treatment $(100 \%$ and $97 \%$ total removal respectively) suggesting that these compounds are highly susceptible to biodegradation while ketoprofen and diclofenac (66\% and 67\% total removal respectively) appear more persistent.
\end{abstract}

Keywords: Pharmaceuticals; Sewage Sludge; HF-LPME; NSAID; Extraction; WWTP; Analysis

\section{Introduction}

Nonsteroidal anti-inflammatory drugs (NSAIDs) is a group of pharmaceuticals characterized by extensive use and high detection frequencies in aquatic environments throughout the world [1-3]. Only in Sweden, approximately 11 tonnes of ketoprofen, 12 tonnes of naproxen, 8 tonnes of diclofenac and 100 tonnes of ibuprofen were sold during 2010 [4]. Several studies have shown evidence of adverse effects on aquatic species of these compounds [5-7]. Today, consensus exists within the scientific community that the main pathway via which these substances reach the environment is through municipal wastewater treatment plant (WWTP) effluents since pharmaceuticals consumed and later excreted by humans will end up in the wastewater stream and thus

"Corresponding author. reach WWTPs [8-10]. The fate of these compounds during the wastewater treatment process thereby becomes a key factor governing to what extent and via which pathways they are released into the environment. If the removal from the water is incomplete during treatment, pharmaceuticals will be released into the aquatic recipent [8] and if significant partitioning into the sewage sludge occurs, they might end up in the terrestrial environment via the application of sludge as a fertilizer onto farmland $[8,11]$.

The overall removal of NSAIDs during wastewater treatment has been investigated in a number of studies, some of which are summarized in Table 1. In general, high removal is obtained for ibuprofen and naproxen, intermediate for ketoprofen and low for diclofenac. It is, however, evident that there are variations between different WWTPs, most likely due to dissimilarities in the operational parameters [12]. 
Table 1. Literature values of overall removal efficiences of NSAIDs in WWTPs applying conventional active sludge treatment.

\begin{tabular}{cccccc}
\hline \multirow{2}{*}{ Analyte } & \multicolumn{5}{c}{ Reference } \\
\cline { 2 - 6 } & {$[8]$} & {$[12]$} & {$[13]$} & {$[14]$} & {$[15]$} \\
\hline Ketprofen & $34 \%^{\mathrm{a}}$ & $86 \%^{\mathrm{b}}$ & $60 \%$ & n.i. & $55 \%$ \\
Naproxen & $55 \%^{\mathrm{a}}$ & $93 \%^{\mathrm{b}}$ & $80 \%$ & $99 \%$ & $72 \%$ \\
Diclofenac & $25 \%^{\mathrm{a}}$ & $57 \%^{\mathrm{b}}$ & $5 \%$ & $72 \%$ & $22 \%$ \\
Ibuprofen & $83 \%^{\mathrm{a}}$ & $100 \%{ }^{\mathrm{b}}$ & $90 \%$ & $91 \%$ & $99 \%$ \\
\hline
\end{tabular}

${ }^{a}$ Average of five WWTPs. ${ }^{b}$ Average of two WWTPs; n.i. not investigated.

NSAIDs are all acids with $\mathrm{pK}_{a}$ values of approximately 4 , which means that they exist more than $90 \%$ as their deprotonated, anionic species in wastewater. The general assumption is therefore that the contribution of partitioning into sludge to the overall removal is very small, partly due to the high water solubility of the ionized species and partly because they are electrostatically repelled by the overall negative charge of sludge particles $[16,17]$. However, up till now, only a few investigations have been performed to experimentally test this theory by measurements in the individual primary, secondary and tertiary sludge collected directly from within the wastewater treatment process. This is mainly attributed to the challenges associated with the extensive sample preparation procedures required for this type of semisolid matrices. A few studies have nevertheless been performed, showing the presence of ketoprofen, naproxen, ibuprofen and diclofenac in samples of primary and secondary sludge from different WWTPs $[8,15,18]$ although not all compounds are found in all samples. In all cases, extensive sample preparation was required consisting of lyophilisation or air-drying followed by pressurized or ultrasonic extraction and finally solid phase extraction clean-up. However, the amounts present in the sludge also have to be related to the overall amounts reaching the WWTP. In a study by Jelić et al., it was shown that the total mass load of naproxen and ketoprofen removed via sludge was more or less zero and for diclofenac $<5 \%$ in three different WWTPs [19]. Sludge water distribution coefficients $\left(\mathrm{K}_{d}\right)$ for ketoprofen, naproxen and ibuprofen in different WWTPs have also been determined and are presented in Table 2. $\mathrm{K}_{d}$ values < $500 \mathrm{~L} / \mathrm{kg}$ are considered low and indicate that the partitioning into sludge can be considered negligible [20]. Thus, the reported $\mathrm{K}_{d}$ values in most cases confirm the theory that only a minor fraction of these compounds are removed via sludge. However, it also becomes evident that large variations are seen between different WWTPs and between different studies and that no clear trend can be observed when primary and secondary sludge are compared. Martín et al. [8] also suggest that the unexpectedly high $\mathrm{K}_{d}$ values obtained in their study could be attributed to a fast biodegradation resulting in low concentrations in the aqueous phase rather than a large partitioning into the sludge phases. It is also noteworthy that to the best of our knowledge, no studies of the partitioning of NSAIDs into tertiary sludge have been performed, most likely due to that tertiary treatment (most often chemical phosphate precipitation) is a less common practice in WWTPs.

In a previous study, we developed a hollow fiber liquid phase membrane extraction (HF-LPME) method for direct extraction of NSAIDs from aqueous suspensions of digested sewage sludge [21]. With this method, time consuming preparations, such as lyophilisation, as well as post-extraction clean up are avoided. The sample is simply suspended in or diluted with ultra pure water before the hollow fiber is immersed. The obtained extract can be directly injected into an HPLC or LC-MS system. Similar set-ups have been developed also by other researchers for different compounds in digested sewage sludge although in those cases the sludge is removed from the suspension prior to the extraction $[23,24]$ or the purpose of the hollow fiber is mainly to protect a solid phase microextraction fiber into which the actual extraction is carried out [25].

The aim of this study was to investigate the fate of ketoprofen, naproxen, diclofenac and ibuprofen in a Swedish WWTP, using the previously developed HF-LPME method.

\section{Methods and Materials}

\subsection{Chemicals and Reagents}

Ibuprofen, ketoprofen and naproxen (all 98\% pure), ammonium carbonate (containing 30\% - 33\% $\mathrm{NH}_{3}$ ) and ammonium acetate were obtained from Sigma Aldrich Chemie GmbH (Steinheim, Germany). Diclofenac sodium salt and di- $n$-hexyl ether was purchased from Sigma Aldrich Inc. (St Louis, MO, USA). Sulphuric acid (Trace select for trace analysis, $\geq 95 \%$ ) was obtained from Sigma Aldrich (Buchs, Switzerland). Methanol (HPLC gradient grade) was purchased from Honeywell Speciality Chemicals (Seelze, Germany) and acetic acid (100\%, glacial) from Merck (Darmstadt, Germany). Ultra pure water from a MilliQ water purification system (Millipore, MA, Billerica, USA) was used.

Individual analyte stock solutions were prepared in methanol and mixed working stock solutions containing 1 or $10 \mathrm{mg} / \mathrm{L}$ of each of the four analytes were diluted in ultra pure water. The acceptor buffer consisted of $0.1 \mathrm{M}$ ammonium carbonate solution at $\mathrm{pH}$ 9. Calibration solutions were prepared from the mixed stock solution by dilution with acceptor buffer. 
Table 2. Literature $K_{d}$ values $(\mathrm{L} / \mathrm{kg}$ ) of NSAIDs detected in primary and secondary sludge from WWTPs applying conventional active sludge treatment.

\begin{tabular}{|c|c|c|c|c|c|c|}
\hline Reference & [8] & & [15] & & [22] & \\
\hline & Primary sludge & Secondary sludge & Primary sludge & Secondary sludge & Primary sludge & Secondary sludge \\
\hline Ketoprofen & n.d. & 200 & 226 & 16 & 40 & 200 \\
\hline Naproxen & $15^{\mathrm{a}}$ & n.r. & n.i. & n.i & 501 & n.r. \\
\hline Ibuprofen & $79^{\mathrm{a}}$ & 17 & 9.5 & 0 & n.r. & 17 \\
\hline Diclofenac & n.d. & 794 & 194 & 118 & 794 & 794 \\
\hline
\end{tabular}

a average of four WWTPs; n.d. not detected; n.r. not reported; n.i. not investigated.

\subsection{Sampling and Studied WWTP}

Källby WWTP is situated in the southwestern part of Lund city in southern Sweden and treats the wastewater from Lund as well as surrounding villages with a total of approximately 86,000 people connected [26]. The plant consists of an initial bar screen, grit removal, primary settling, secondary conventional active sludge (CAS) treatment with anoxic pre-denitrification and tertiary phosphate precipitation with ferric chloride (Figure 1).

For method evaluation experiments, grab sampling of water and sludge from the different treatment steps was performed. Samples were homogenized using an UltraTurrax T25 homogenizer from IKA Werke (Staufen, Germany). Prior to the extraction, the samples were diluted with ultra pure water and $\mathrm{pH}$ was adjusted to 2 with concentrated sulphuric acid.

For the final analysis, grab samples were collected of influent water (In) and water and sludge leaving the primary treatment (P out and PS) on the $26^{\text {th }}$ September 2011. Samples were homogenized and diluted 10 times with ultra pure water whereafter the $\mathrm{pH}$ was adjusted to 2 . The homogenizer was carefully washed with detergent, followed by methanol and reagent water between the different samples to avoid cross contamination. All samples were extracted within the same week. Grab samples of water and sludge leaving the secondary (S out and SS) and tertiary treatment (Out and TS) were collected on the $3^{\text {rd }}$ of October 2011 and treated in the same way apart from that all samples except the secondary sludge were instead diluted 5 times. The dilution factors were optimized by preliminary experiments. Water and sludge from the secondary treatment were extracted during the same week and tertiary sludge as well as effluent water in the beginning of the following week. Additional sampling of influent water was also performed on the $31^{\text {st }}$ of January and $18^{\text {th }}$ of February 2013.

\subsection{HF-LPME}

The extraction procedure was described earlier [21]. Briefly, PP50/280 Accurel ${ }^{\mathbb{B}}$ polypropylene hollow fiber membranes, wall thickness of $50 \mu \mathrm{m}, 0.1 \mu \mathrm{m}$ pore size and i.d. of $280 \mu \mathrm{m}$ (Membrana GmbH, Wuppertal, Germany), were cut into $20 \mathrm{~cm}$ long pieces, washed in methanol and air dried prior to the extraction. The lumen of each fiber was filled with acceptor buffer using a syringe with $0.3 \mathrm{~mm}$ needle diameter (BD Micro-Fine ${ }^{\mathrm{TM}}+$ Demi, Becton, Dickinson and Company, USA). Thereafter the porous wall was impregnated by dipping the fiber into di-n-hexyl ether for 1 minute. The fiber was then quickly immersed into ultra pure water to wash off surplus di-n-hexyl ether. Fresh acceptor buffer was pushed through the fiber with the syringe to ensure it was totally filled and the ends were sealed. The fiber was then coiled into a loop and a piece of copper wire was attached around it as a weight before it was immersed into the sample. Extraction was performed under the conditions optimized in the previous study [21] using $50 \mathrm{~mL}$ sample volume, 4 hours extraction time and stirring at $660 \mathrm{rpm}$ using a magnetic stirrer (RO10 Power, IKA Werke).

After extraction, the fiber was removed from the sample, the ends cut open with a scalpel and carefully wiped off with a Kleenex tissue before an air-filled syringe was attached to the fiber and the acceptor solution was pushed out into a $2 \mathrm{~mL}$ vial with a $\mu \mathrm{L}$ insert. The volume of the collected acceptor was determined by weighing the vial before and after filling it. The volumes were approximately $10 \mu \mathrm{L}$. To increase the volume of the extract before LC injection to permit duplicate injections if needed, it was then diluted two times by addition of ultra pure water and sonicated for a few minutes to ensure complete mixing before it was injected into the LCMS/MS.

\subsection{LC-MS/MS Analysis}

Analysis was performed on an API Q-Star Pulsar I quadropole time of flight mass spectrometer with a Turboion electrospray interface from Applied Biosystems (Carlsbad, California, USA) coupled to an Ultimate pump and Famos autosampler originally from LC Packings (Thermo Scientific, Waltham, MA, USA) and a CSI 


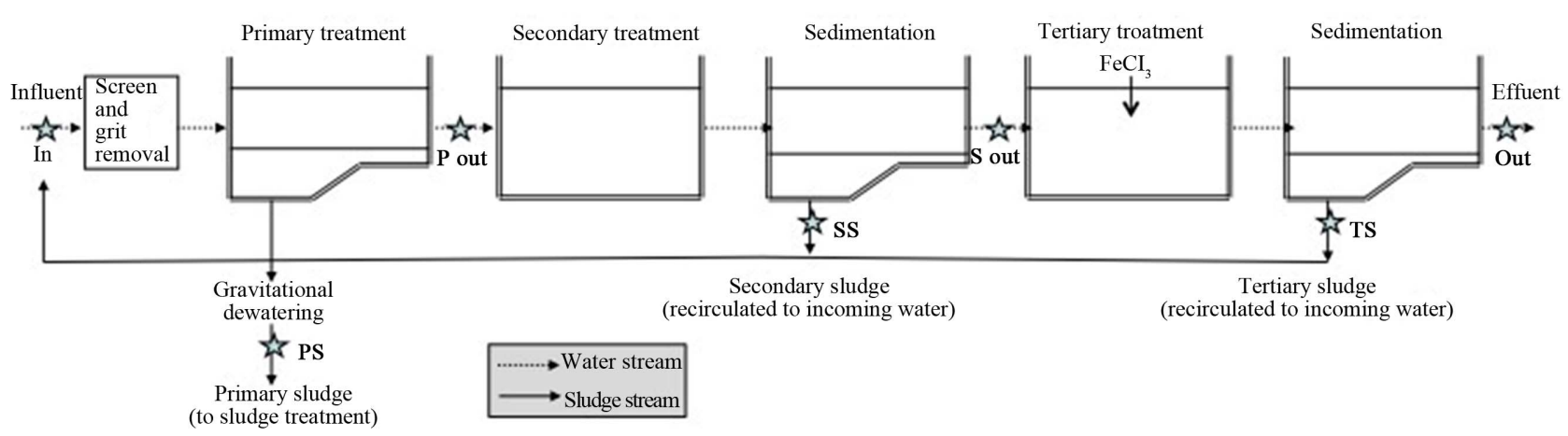

Figure 1. The treatment process at Källby WWTP. After passing the screen and grit chamber, the water undergoes primary treatment (pre-sedimentation), secondary treatment (CAS) and tertiary treatment (chemical phosphate precipitation). Sampling points for the study (abbreviations in bold) are marked with stars.

6150 vacuum degasser (Cambridge Scientific Instruments, Cambridge, UK). The injection volume was $4 \mu \mathrm{L}$ and the injection was performed in $\mu \mathrm{L}$ pick-up mode.

Chromatographic separation was performed on an XDB C-18 column (particle size $5 \mu \mathrm{m}, 4.6 \times 140 \mathrm{~mm}$ ) protected by a Security Guard KJ0-4282 pre-column with $\mathrm{C}_{18}$ sorbent from Phenomenex (Torrance, CA, USA). The mobile phase liquids employed were $10 \mathrm{mM}$ ammonium acetate (adjusted to $\mathrm{pH} 4$ with $100 \%$ acetic acid) and $100 \%$ methanol. Gradient elution was performed, starting with $70 \%$ methanol and increasing to $95 \%$ in $3.5 \mathrm{~min}$ followed by isocratic elution to $10 \mathrm{~min}$ and return to initial conditions in $1 \mathrm{~min}$. An equilibration time of $5 \mathrm{~min}$ was used prior to next injection. Prior to each analysis batch of sample extracts, a standard solution of $500 \mu \mathrm{g} / \mathrm{L}$ was injected several times to determine the instrument repeatability followed by injection of six standard solutions with concentrations of $0,250,500,1000,1500$ and $2000 \mu \mathrm{g} / \mathrm{L}$ respectively for construction of a calibration curve.

For the MS/MS analysis the ion spray voltage was set to $-4500 \mathrm{~V}$ and the ion source temperature to $400^{\circ} \mathrm{C}$. Focusing potential and declustering potential 2 were set to -220 and $-10 \mathrm{~V}$ respectively and a collision gas setting of 5 units was used. Other parameters were optimized for each target ion and are presented in Table 3.

\subsection{Standard Addition and Calculations}

The theory behind HF-LPME from aqueous samples has been extensively reviewed elsewhere [27-29]. In short, the principle for extraction of acidic analytes, such as NSAIDs, is based on acidification of the sample to protonate the analytes. These thereby become uncharged and diffuse via an organic solvent immobilized in the porous wall of a polypropylene hollow fiber into a basic acceptor solution held in the lumen of the fiber. In the acceptor, the analytes are deprotonated and hence charged which
Table 3. Analyte dependent mass spectrometry parameters.

\begin{tabular}{ccccc}
\hline \multirow{3}{*}{ Analyte } & \multicolumn{4}{c}{ MS/MS parameters } \\
\cline { 2 - 5 } & $\begin{array}{c}\text { Collision } \\
\text { Energy (eV) }\end{array}$ & $\begin{array}{c}\text { Declustering } \\
\text { Potential (V) }\end{array}$ & $\begin{array}{c}\text { Precursor } \\
\text { ion }\end{array}$ & $\begin{array}{c}\text { Product } \\
\text { ion }\end{array}$ \\
\hline Ketoprofen & -12 & -40 & 253 & 209.10 \\
Naproxen & -10 & -20 & 229 & 185.10 \\
Diclofenac & -10 & -20 & 294 & 250.02 \\
Ibuprofen & -10 & -20 & 205 & 106.13 \\
\hline
\end{tabular}

means that they cannot diffuse back through the solvent and are thereby trapped. The extraction can be evaluated based on the enrichment factor, $E_{e}$, (Equation (1)) where $c_{s}$ is the initial concentration in the sample and $c_{a}$ is the measured concentration in the acceptor after the extraction.

$$
E_{e}=\frac{C_{a}}{C_{s}}
$$

Extraction from suspensions of solid and semi-solid matrices is a rather new development and requires a somewhat different quantification procedure since two interconnected equilibria exist, presented in Equation (2) where $\mathrm{A}_{\text {bound }}$ is the analyte sorbed to the solid particles or associated with dissolved organic matter in the sample, $\mathrm{A}_{\text {diss }}$ is the freely dissolved analyte in the sample and $\mathrm{A}_{\text {ext }}$ is the analyte extracted into the acceptor.

$$
\mathrm{A}_{\text {bound }} \rightleftharpoons \mathrm{A}_{\text {diss }} \rightleftharpoons \mathrm{A}_{\text {ext }}
$$

In an earlier study, a modified standard addition approach for the quantification of extractable analytes in such systems was developed and discussed [21]. The same approach was applied in this study. For each matrix, $50 \mathrm{~mL}$ samples were spiked with $0,0.25,0.50$ and 0.75 $\mu \mathrm{g} / \mathrm{L}$ of each analyte $(\mathrm{n}=3)$ prior to extraction. The measured concentration in the acceptor was then plotted versus the concentration added to the sample and the 
initial concentration in the sample was determined as the intercept of the obtained regression line with the $\mathrm{x}$-axis. Matrix specific $E_{e}$ values were determined as the slope of the regression line for each single analyte and matrix. By comparison with pressurized hot water extraction it was earlier shown both for NSAIDs [30] and for antidepressants [31] in digested sludge that the HF-LPME extraction technique gives results equivalent with exhaustive extraction.

The limit of detection (LOD) and limit of quantification (LOQ) of the chromatographic analysis were estimated as 3 and 10 times the baseline noise, respectively. The overall method detection limit (MDL) was then determined by division of the LOD with $E_{e}$ for each specific matrix.

\section{Results}

The applied HF-LPME method provided enrichment factors $>1000$ times for all matrices and analytes (Figure 2).

The LOD values for ketoprofen, naproxen, ibuprofen and diclofenac were $2,17,17$ and $20 \mu \mathrm{g} / \mathrm{L}$ respectively, and the LOQ values 3.3 times higher. The linearity of the standard addition curves and the overall method detection limit (MDL) for each analyte and sample are presented in Table 4. Concentrations in each sample were calculated from the standard addition curves and are presented together with flow data from the WWTP for the sampling dates in Table 4.

The calculated concentrations were then multiplied by the current flow of the different sludge and water streams to obtain the load of each analyte in g/day. The flowcorrected amounts of the four NSAIDs found in each sample are presented in Figure 3. The relative standard deviation of the calculated amounts ranged between $7 \%$ and $16 \%$. An example of a standard addition curve (ketoprofen in influent water) is presented in Figure 4.

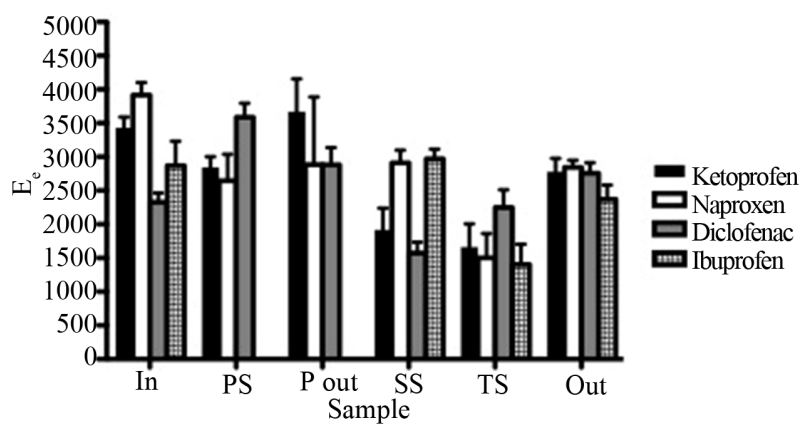

Figure 2. Enrichment factors $\left(E_{e}\right)$ for the different analytes and samples. In the PS and $P$ out samples, no ibuprofen was detected. Due to instrumental errors, enrichment factors could not be calculated for $S$ out. Error bars denote the standard deviation $(n=3)$.

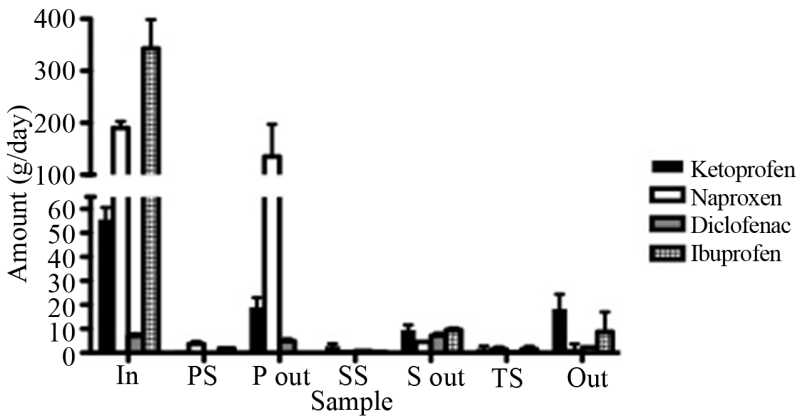

Figure 3. Detected amounts of the four NSAIDs in the different phases in the wastewater treatment process. Error bars denote the standard deviation $(n=3)$. In the PS and P out samples, no ibuprofen was detected.

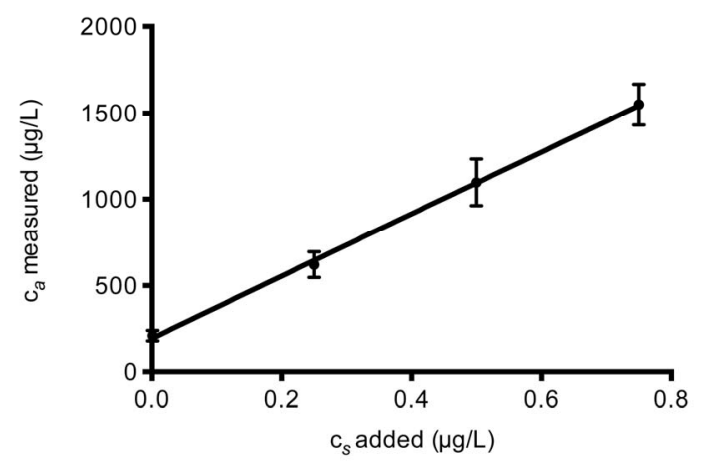

Figure 4. Standard addition curve for ketoprofen in influent water diluted 10 times with the added concentrations of 0 , $0.25,0.50$ and $0.75 \mu \mathrm{g} / \mathrm{L}$. Error bars denote the standard deviation $(n=3)$.

The obtained values were applied for calculations of a mass balance for each analyte, which is presented in Figure 5. This was performed by division of the flow corrected amount in each sample with the amount present in influent water. Percentage values are rounded off to the nearest integer.

A comparison of the detected concentrations in influent water between the $26^{\text {th }}$ September 2011 and $31^{\text {st }}$ January as well as $18^{\text {th }}$ February 2013 is presented in Figure 6.

\section{Discussion}

This study shows the presence of all four NSAIDs in the WWTP influent at all three sampling occasions with the highest amounts detected of ibuprofen in all cases. This is in accordance with the sales data, showing that ibuprofen is the most heavily consumed of the four NSAIDs in Sweden.

Regarding the overall removal, a similar pattern is observed as in previous studies, i.e. ibuprofen and naproxen express high removal efficiencies $(97 \%$ and $100 \%$ removal respectively) whereas diclofenac and ketoprofen 
Table 4. Performance of the method for quantification of analytes in the samples expressed as the linearity of the standard addition curve $\left(\mathrm{R}^{2}\right)$, the determined initial concentration in each sample $\left(c_{i}\right)$ and the overall method detection limit (MDL). Data based on standard addition with the spiking concentrations $0,0.25,0.50$ and $0.75 \mu \mathrm{g} / \mathrm{L}$, triplicates analyzed for all concentrations for all matrices.

\begin{tabular}{|c|c|c|c|c|c|c|c|}
\hline Analyte & Matrix & & & & & & \\
\hline & In & PS & P out & SS & S out & TS & Out \\
\hline \multicolumn{8}{|l|}{ Ketoprofen } \\
\hline Linearity $\left(\mathrm{R}^{2}\right)$ & 0.979 & 0.972 & 0.935 & 0.897 & 0.960 & 0.824 & 0.952 \\
\hline$c_{i}(\mu \mathrm{g} / \mathrm{L})$ & 2.4 & 2.2 & 0.8 & 3.0 & 0.4 & 1.9 & 0.8 \\
\hline Flow (m³/day) & 23,174 & 352 & 24,708 & 930 & 23,967 & 950 & 23,017 \\
\hline $\operatorname{MDL}(\mathrm{ng} / \mathrm{L})$ & 0.6 & 0.8 & 0.6 & 1.1 & 0.3 & 1.3 & 0.8 \\
\hline \multicolumn{8}{|l|}{ Naproxen } \\
\hline Linearity $\left(\mathrm{R}^{2}\right)$ & 0.980 & 0.834 & 0.676 & 0.964 & 0.977 & 0.776 & 0.988 \\
\hline$c_{i}(\mu g / L)$ & 8.2 & 10.6 & 5.6 & 0.36 & 0.19 & 1.5 & 0.03 \\
\hline Flow (m³/day) & 23,174 & 352 & 24,708 & 930 & 23,967 & 950 & 23,017 \\
\hline $\operatorname{MDL}(\mathrm{ng} / \mathrm{L})$ & 4.4 & 6.5 & 6.0 & 5.9 & 2.1 & 11.5 & 6.1 \\
\hline \multicolumn{8}{|l|}{ Diclofenac } \\
\hline Linearity $\left(\mathrm{R}^{2}\right)$ & 0.965 & 0.971 & 0.969 & 0.905 & 0.970 & 0.036 & 0.971 \\
\hline$c_{i}(\mu \mathrm{g} / \mathrm{L})$ & 0.30 & 0.24 & 0.20 & 0.78 & 0.30 & 0.14 & 0.10 \\
\hline Flow (m³/day) & 23,174 & 352 & 24,708 & 930 & 23,967 & 950 & 23,017 \\
\hline $\operatorname{MDL}(\mathrm{ng} / \mathrm{L})$ & 7.3 & 4.8 & 5.9 & 10.8 & 2.4 & 7.6 & 6.2 \\
\hline \multicolumn{8}{|l|}{ Ibuprofen } \\
\hline Linearity $\left(\mathrm{R}^{2}\right)$ & 0.783 & d.n & d.n & 0.977 & 0.922 & 0.817 & 0.933 \\
\hline $\mathrm{c}_{\mathrm{i}}(\mu \mathrm{g} / \mathrm{L})$ & 14.8 & d.n & d.n & 0.04 & 9.6 & 7.2 & 0.38 \\
\hline Flow (m³/day) & 23,174 & 352 & 24,708 & 930 & 23,967 & 950 & 23,017 \\
\hline $\operatorname{MDL}(\mathrm{ng} / \mathrm{L})$ & 7.0 & d.n. & d.n & 6.7 & 4.3 & 14.3 & 8.4 \\
\hline
\end{tabular}
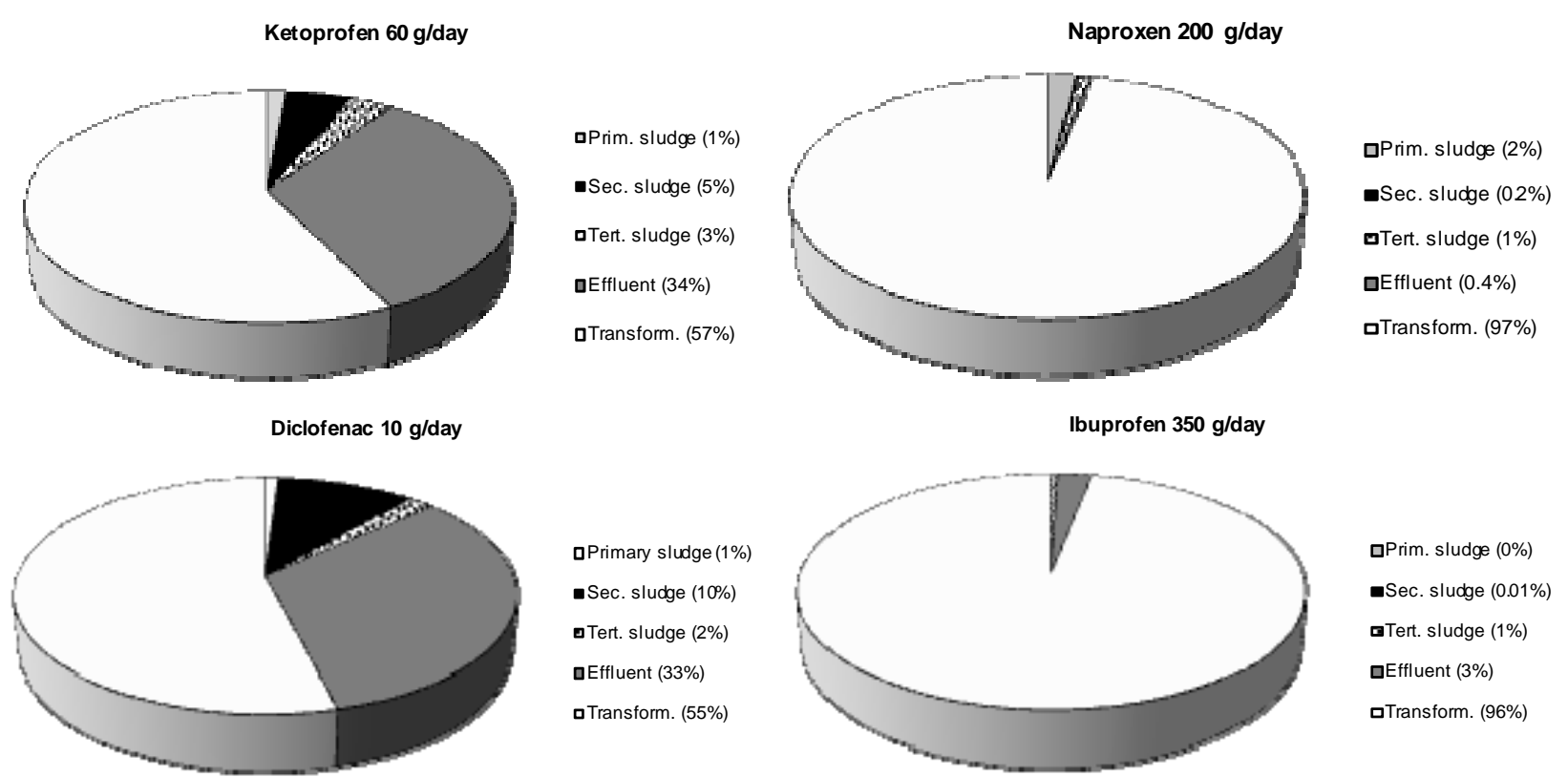

Figure 5. The fraction of the different NSAIDs present in the influent detected in the different sludge phases and the effluent respectively. The fraction not detected in the sludge or the effluent is considered to be transformed into other compounds. All values $>1 \%$ are rounded off to the nearest integer. 


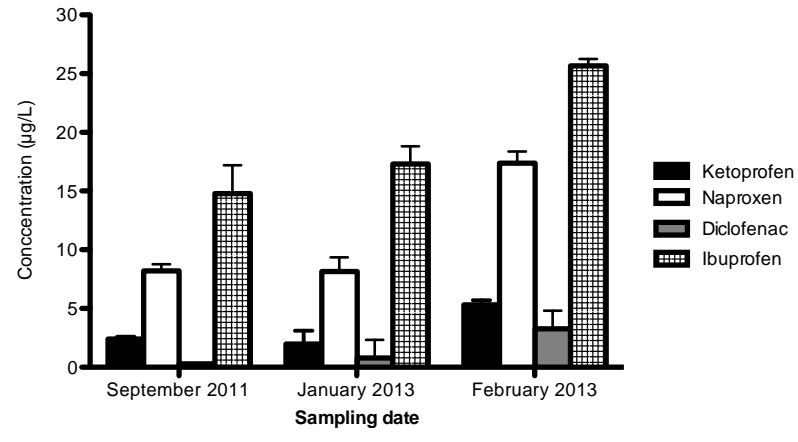

Figure 6. Detected concentrations in the influent in September 2011 as well as January and February 2013. Error bars denote the standard deviation $(n=3)$.

are removed to a lesser extent $(67 \%$ and $66 \%$ respectively). Thus, ketoprofen is the most abundant substance in the effluent ( $19 \mathrm{~g} /$ day) even though naproxen and ibuprofen are both present in much higher amounts in the influent water.

Two major removal mechanisms are present in a WWTP: a) partitioning into sludge, and b) biological transformation or degradation [32]. The results obtained in this study confirm existing theories that only a minor fraction of all four of the NSAIDs reaching the WWTP partition into and are thus removed via the sludge. In this work, we wanted to investigate, not only the total sludge removal, but also the partitioning into each individual sludge type obtained in the investigated WWTP. Primary, secondary and tertiary sludge possess different physical as well as chemical properties such as particle size, specific surface, water content and chemical composition which could potentially lead to different affinities for the NSAIDs $[33,34]$. The results from this study could, however, not verify such differences. It's true that for both ketoprofen and diclofenac, the largest partitioning took place into secondary sludge (5\% and $10 \%$ respectively), but both for naproxen and ibuprofen less than $1 \%$ ended up in the secondary sludge. Thus, secondary sludge cannot, in general, be considered to possess a higher affinity for NSAIDs than the other sludge types. The mechanisms behind sorption of polar ionics to different types of solid matrices is still not completely understood and the finding that the partitioning into the same sludge type (secondary sludge) varies between $10 \%$ and $<1 \%$ for the different NSAIDs even though they possess such structural similarities is highly interesting and should be further investigated. It is, however, clear that it is not hydrophobicity alone, which governs this process. Diclofenac, which exhibits the largest partitioning into sludge (secondary sludge as well as total), is also the most hydrophobic of the four NSAIDs $(\log \mathrm{D}=1.77$ at $\mathrm{pH} 7)$, which could be considered the explanation for its larger sludge partitioning. However, ketoprofen has by far the lowest $\log \mathrm{D}$ value of the four NSAIDs (0.19), but still expresses a larger sludge partitioning ( $9 \%$ in total) than naproxen $(\log \mathrm{D}=0.73,3 \%$ overall sludge removal) and ibuprofen $(\log \mathrm{D}=0.94,1 \%$ overall sludge removal) which contradicts the theory that hydrophobicity alone governs the sorption process. It has been suggested that mechanisms such as hydrogen bonding, $\pi$ - $\pi$ interactions and cation bridging also plays important parts in the sorption of polar ionic substances to different solid matrices although these mechanisms are still not thouroghly investigated and further studies on this matter are needed [35]. Log D values for the NSAIDs at $\mathrm{pH} 7$ were obtained from the SciFinder database (C) 2006 American Chemical Society).

The percentage values do, however, not provide the whole picture due to the large differences in concentrations between the compounds in the influent. When considering the absolute amounts, the highest detected amount was found for naproxen in primary sludge (4 g/day) followed by ketoprofen in secondary sludge (3 $\mathrm{g} /$ day). Even though only a minor fraction of these compounds partitions into the sludge, detectable amounts are found of all NSAIDs in at least two of the sludge types. This corresponds well with previous studies where we have shown the presence of all four NSAIDs in digested sludge from the same WWTP at the ng/g level at repated sampling occasions [21,30]. In a previous study, we have also shown that after six months storage, which proceeds the application onto farmland, ketprofen and naproxen are no longer detected in the digested sludge and the concentrations of diclofenac and ibuprofen are decreased [36]. When this sludge was used for fertilization of wheat and soybean in a greenhouse experiment, no uptake into crops of neither diclofenac nor ibuprofen could be detected. However, the toxicity of NSAIDs as well as other pharmaceuticals to terrestrial organisms is still to a great extent unkown and since detectable amounts are present in the final, digested sludge, potential risks to the terrestrial environment cannot be fully ruled out.

In spite of the small partitioning into sludge, two of the analytes, naproxen and ibuprofen, were still efficiently removed during the wastewater treatment and in both cases the major removal took place during the secondary treatment, thus indicating an efficient biological degradation during the CAS process. The degradation is usually divided into mineralization which denotes the total degradation to inorganic species such as $\mathrm{CO}_{2}, \mathrm{H}_{2} \mathrm{O}$ or $\mathrm{HCl}$ and transformation which describes the incomplete degradation to other organic compounds which could in turn partition into the sludge or be released via the effluent [37]. Laboratory batch studies have shown that naproxen 
is degraded during active sludge treatment under the formation of o-desmethoxynaproxen (2-(6-hydroxynaphtalen-2-yl)propionic acid) which is also a human naproxen metabolite $[38,39]$. Further, the formation of the human ibuprofen metabolites 1- and 2-hydroxyibuprofen has been shown in similar experiments [38]. Thus it is likely to assume that these compounds could be formed during CAS treatment also in real WWTPs and be released via the effluent. The toxicity of these transformation products are to a great extent still unknown, although estimations performed by Leinert et al. suggest that transformation of ibuprofen into its main metabolites decreases the toxicity towards freshwater organisms [40]. On the other hand, studies have shown that certain phototransformation products of NSAIDs might actually have a higher aquatic toxicity than the parent compound themselves [41,42]. Thus, the transformation during wastewater treatment and potential release of transformation products into the environment is an important aspect to study.

The obtained results for ketoprofen and diclofenac showed only partial overall removal for both of these substances (approx. 65\% overall removal during the treatment). These compounds expressed the largest sludge partitioning, which means that the low overall removal must be associated with limited biodegradability. Previous studies have shown the persistence of diclofenac during aerobic as well as anaerobic biodegradation experiments [39], although hydroxylated transformation products have been found in some cases [43]. Quintana et al. [38] have also shown the formation of two ketoprofen transformation products during active sludge batch experiments: 3-(hydroxy-carboxymethyl) hydratopic acid and 3-(keto-carboxymethyl)hydratopic acid.

This study was performed on samples collected from inside an actual WWTP. The advantage of such a study is that the behaviour of the substances is studied under real conditions, which could never be totally mimicked in the laboratory. However, it also possesses a few disadvantages. The number of sample types analyzed (totally seven different) provides an overview of the whole water treatment process, but also reduces the number of replicates possible to analyze due to time limits. This means that samples are collected for real analysis only once, i.e. the study will provide a snapshot of the processes in this specific WWTP at one single occasion. The consumption of NSAIDs as well as the inflow to the WWTP might vary over the year. Also samples are collected from the first steps at one occasion and from the latter ones one week later based on the assumption that the variation in concentrations in incoming water is negligible over this period of time. To test this assumption, additional sampling and analysis of influent water are performed in
January and February 2013. In all three cases, all four substances are found in the influent in the same proportions. The higher amounts detected in February could be due to the Swedish flu season, usually peaking at this time of the year. It is our opinion that the study shows that sludge removal of NSAIDs is of minor importance and the major part of the total removal is caused by other mechanisms, all in agreement with existing theories.

The study also shows that the applied direct HF-LPME method is applicable for all these matrices. It is cheap, simple, environmental friendly and results in efficient enrichment and clean-up. The method provides high enrichment factors (>1000 times) for even the most complex matrices, such as primary sludge, contributing to its applicability also on very particulate or even solid samples. This is also illustrated by the low method detection limits. Up till now, rather few measurements have been performed on sludge samples from within WWTPs due to the complex analytical procedures required. The developed HF-LPME method can facilitate future measurements in WWTPs to increase the understanding of the fate of pharmaceuticals as well as other polar pollutants during wastewater treatment.

\section{Acknowledgements}

The authors wish to express their gratitude towards PerÅke Rask and colleagues at Källby STP/VA Syd for help with sampling as well as Michael Cimbritz and Jan Svensson for providing technical information about the plant. Warmest thanks to Maria Mases for providing flow data and help with the calculations and MSc student Said al-Hamimi who performed the analysis of influent samples from 2013. Region Skåne (the regional government in Scania), RECETO (PhD programme of environmental chemistry, microbiology and toxicology), Copenhagen, and the Royal Physiographic Society, Lund, are greatly acknowledged for funding.

\section{REFERENCES}

[1] I. Maijó, F. Borrull, C. Aguilar and M. Calull, "Determination of Anti-Inflammatory Drugs in River Water by sweeping-Micellarelectrokinetic Capillary Chromatography," Journal of Liquid Chromatography and Related Technologies, Vol. 35, No. 15, 2012, pp. 2134-2147.

[2] N. Migowska, M. Caban, P. Stepnowski and J. Kumirska, "Simultaneous Analysis of Non-Steroidal Anti-Inflammatory Drugs and Estrogenic Hormones in Water and Wastewater Samples Using Gas Chromatography-Mass Spectrometry and Gas Chromatography with Electron Capture Detection," Science of the Total Environment, Vol. 441, 2012, pp. 77-88.

[3] M. Villar Navarro, M. Ramos Payan, R. Fernández-Torres, M. A. Bello-López, M. Callejón and M. A. Guiráum- 
Pérez, "Capillary Electrophoresis Determination of Nonsteroidal Anti-Inflammatory Drugs in Wastewater Using Hollow Fiber Liquid-Phase Microextraction," Electrophoresis, Vol. 32, No. 16, 2011, pp. 2107-2113. doi:10.1002/elps.201100105

[4] Apotekens Service (Service of the Pharmacies), Sales Data for Pharmaceuticals in Sweden, 2011.

[5] B. Quinn, F. Gagné and C. Blaise, "The Effects of Pharmaceuticals on the Regeneration of the Cnidarian, Hydra attenuata," Science of the Total Environment, Vol. 402, No. 1, 2008, pp. 62-69. doi:10.1016/j.scitotenv.2008.04.039

[6] B. Quinn, F. Gagné and C. Blaise, "Evaluation of the Acute, Chronic and Teratogenic Effects of a Mixture of Eleven Pharmaceuticals on the Cnidarian, Hydra attenuata," Science of the Total Environment, Vol. 407, No. 3, 2009, pp. 1072-1079. doi:10.1016/j.scitotenv.2008.10.022

[7] A. C. Mehinto, E. M. Hill and C. R. Tyler, "Uptake and Biological Effects of Environmentally Relevant Concentrations of the Nonsteroidal Anti-inflammatory Pharmaceutical Diclofenac in Rainbow Trout (Oncorhynchus mykiss)," Environmental Science and Technology, Vol. 44, No. 6, 2010, pp. 2176-2182. doi:10.1021/es903702m

[8] J. Martín, D. Camacho- Muñoz, J. L. Santos, E. Aparicio and E. Alonso, "Occurence of Pharmaceutical Compounds in Wastewater and Sludge from Wastewater Treatment Plants: Removal and Ecotoxicological Impact of Wastewater Discharges and Sludge Disposal," Journal of Hazardous Materials, Vol. 239-240, 2012, pp. 40-47.

doi:10.1016/j.jhazmat.2012.04.068

[9] A. Jelic, M. Gros, A. Ginebreda, R. Cespedes-Sánchez, F. Ventura, M. Petrovic and D. Barceló, "Occurence, Partition and Removal of Pharmaceuticals in Sewage Water and Sludge during Wastewater Treatment," Water Research, Vol. 45, No. 3, 2011, pp. 1165-1176. doi:10.1016/j.watres.2010.11.010

[10] R. L. Oulton, T. Kohn and D. M. Cwiertny, "Pharmaceuticals and Personal Care Products in Effluent Matrices: A Survey of Transformation and Removal during Wastewater Treatment and Implications for wastewater management," Journal of Environmental Monitoring, Vol. 12, No. 11, 2010, pp. 1956-1978. doi:10.1039/c0em00068j

[11] P. Gao, Y. Ding, H. Li and I. Xagoraraki, "Occurence of Pharmaceuticals in a Municipal Wastewater Treatment Plant: Mass Balance and Removal Processes," Chemosphere, Vol. 88, No. 1, 2012, pp. 17-24. doi:10.1016/j.chemosphere.2012.02.017

[12] V. G. Samaras, A. S. Stasinakis, D. Mamais, N. S. Thomaidis and T. D. Lekkas, "Fate of Selected Pharmaceuticals and Syntehtic Endocrine Disrupting Compounds during Wastewater Treatment and Sludge Anaerobic Digestion," Journal of Hazardous Materials, Vol. 244-245, 2013, pp. 259-267. doi:10.1016/j.jhazmat.2012.11.039

[13] P. Falås, H. R. Andersen, A. Ledin and J. La Cour Jansen, "Occurrence and Reduction of Pharmaceuticals in the Water Phase at Swedish Wastewater Treatment Plants," Water Science and Technology, Vol. 66, No. 4, 2012, pp. 783-791. doi:10.2166/wst.2012.243
[14] Q. Huang, Y. Yu, C. Tang, K. Zhang, J. Cui and X. Peng, "Occurrence and Behavior of Non-Steroidal Anti-Inflammatory Drugs and Lipid Regulators in Wastewater and Urban River Water of the Pearl River Delta, South China," Journal of Environmental Monitoring, Vol. 13, 2011, pp. 855-863. doi: $10.1039 / \mathrm{c} 1 \mathrm{em} 10015 \mathrm{~g}$

[15] J. Radjenovic, M. Petrovic and D. Barcelo, "Fate and Distribution of Pharmaceuticals in Wastewater and Sewage Sludge of the Conventional Activated Sludge (CAS) and Advanced Membrane Bioreactor (MBR) Treatment," Water Research, Vol. 43, No. 3, 2009, pp. 831-841. doi:10.1016/j.watres.2008.11.043

[16] D. Bendz, N. A. Paxéus, T. R. Ginn and F. J. Loge, "Occurrence and Fate of Pharmaceutically Active Compounds in the Environment, a Case Study: Höje River in Sweden," Journal of Hazardous Materials, Vol. 122, No. 3, 2005, pp. 195-204. doi:10.1016/j.jhazmat.2005.03.012

[17] M. Carballa, F. Omil, J. M. Lema, M. Llompart, C. García-Jares, I. Rodríguez, M. Gómez and T. Ternes, "Behavior of Pharmaceuticals, Cosmetics and Hormones in a Sewage Treatment Plant," Water Research, Vol. 38, No. 12, 2004, pp. 2918-2926. doi:10.1016/j.watres.2004.03.029

[18] J. Martín, M. D. Camacho Muñoz, J. L. Santos, I. Aparicio and E. Alonso, "Distribution and Temporal Evolution of Pharmaceutically Active Compounds Alongside Sewage Sludge Treatment. Risk Assessment of Sludge Application onto Soils," Journal of Environmental Management, Vol. 102, 2012, pp. 18-25. doi:10.1016/i.jenvman.2012.02.020

[19] A. Jelic, M. Petrovic and D. Barceló, "Multi-Residue Method for Trace Level Determination of Pharmaceuticals in Solid Samples Using Pressurized Liquid Extraction Followed by Liquid Chromatography/QuadropoleLinear Ion Trap," Talanta, Vol. 80, No. 1, 2009, pp. 363371. doi:10.1016/j.talanta.2009.06.077

[20] T. A. Ternes, N. Herrmann, M. Bonerz, T. Knacker, H. Siegrist and A. Joss, "A Rapid Method to Measure the Solid-Water Distribution Coefficient $\left(\mathrm{K}_{d}\right)$ for Pharmaceuticals and Musk Fragrances in Sewage Sludge," Water Research, Vol. 38, No. 19, 2004, pp. 4075-4084. doi:10.1016/j.watres.2004.07.015

[21] E. Sagristà, E. Larsson, M. Ezoddin, M. Hidalgo, V. Salvadó and J. Å. Jönsson, "Determination of Non-Steroidal Anti-Inflammatory Drugs in Sewage Sludge by Direct Hollow Fiber Supported Liquid Membrane Extraction and Liquid Chromatography-Mass Spectrometry," Journal of Chromatography A, Vol. 1217, No. 40, 2010, pp. 6153-6158. doi:10.1016/j.chroma.2010.08.005

[22] T. Okuda, N. Yamashita, H. Tanaka, H. Matsukawa and K Tanabe, "Development of Extraction Method of Pharmaceuticals and Their Occurrences Found in Japanese Wastewater Treatment Plants," Environment International, Vol. 35, No. 20, 2009, pp. 815-820. doi:10.1016/j.envint.2009.01.006

[23] H. Jiang, B. Hu, B. Chen and W. Zu, "Hollow Fiber Liquid Phase Microextraction Combined with Graphite Furnace Atomic Absorbtion Spectrometry for the Determination of Methylmercury in Human Hair and Sludge Sam- 
ples," Spectrochimca Acta, Part B, Vol. 63, No. 7, 2008, pp. 770-776. doi:10.1016/j.sab.2008.04.011

[24] T. Vasskog, O. Bergersen, T. Anderssen, E. Jenssen and T. Eggen, "Depletion of Selective Serotonine Reuptake Inhibitors during Sewage Sludge Composting," Waste Management, Vol. 29, No. 11, 2009, pp. 2808-2815.

[25] C. Basheer and H. K. Lee, "Hollow Fiber MembraneProtected Solid-Phase Microextraction of Triazine Herbicides in Bovine Milk and Sewage Sludge Samples," Journal of Chromatography A, Vol. 1047, No. 2, 2004, pp. 189-194.

[26] V. A. Syd, "Environmental Report," 2011. http://www.vasyd.se/SiteCollectionDocuments/Vatten $\% 2$ 0och\%20avlopp/Avloppsvatten/Miljörapporter/Miljörapp ort_2010_Källby.pdf

[27] K. F. Bårdstu, T. S. Ho, K. E. Rasmussen, S. PedersenBjergaard and J. Å. Jönsson, "Supported Liquid Membranes in Hollow Fiber Liquid Phase Microextraction (LPME). Practical Considerations in the Three-Phase Mode," Journal of Separation Science, Vol. 30, No. 9, 2007, pp. 1364-1370. doi:10.1002/jssc. 200600486

[28] H. K. Lee, K. E. Rasmussen and S. Pedersen-Bjergaard, "Environmental and Bioanalytical Applications of Hollow Fiber Membrane Liquid-Phase Microextraction: A Review," Analytica Chimica Acta, Vol. 624, No. 2, 2008, pp. 253-268. doi:10.1016/j.aca.2008.06.050

[29] J. Å. Jönsson, "Membrane Extraction: General Overview and Basic Techniques," In: J. Pawliszyn and H. Lord, Eds., Comprehensive Sampling and Sample Preparation, Academic Press, Oxford, 2012, pp. 461-474. doi:10.1016/B978-0-12-381373-2.00049-1

[30] A. Saleh, E. Larsson, Y. Yamini and J. Å. Jönsson, "Hollow Fiber Liquid Phase Microextraction as a Preconcentration and Clean-Up Step after Pressurized Hot Water Extraction for the Determination of Non-Steroidal AntiInflammatory Drugs in Sewge Sludge," Journal of Chromatography A, Vol. 1218, No. 10, 2011, pp. 1331-1339. doi:10.1016/j.chroma.2011.01.011

[31] E. Sagristà, J. M. Cortés, E. Larsson, V. Salvadó, M. Hidalgo and J. Å. Jönsson, "Comparison of Two Extraction Methods for the Determination of Selective Serotonine Reuptake Inhibitors in Sewage Sludge by Hollow Fiber Liquid Phase Microextraction," Journal of Separation Science, Vol. 35, 2012, pp. 2460-2468. doi:10.1002/jssc.201200257

[32] R. Seth, E. Webster and D. Mackay, "Continued Development of a Mass Balance Model of Chemical Fate in a Sewage Treatment Plant," Water Research, Vol. 42, No. 3, 2008, pp. 595-604. doi:10.1016/j.watres.2007.08.004

[33] I. S. Turovskiy and P. K. Mathai, "Wastewater Sludge Processing," John Wiley and Sons, Inc., Hoboken, 2006. doi:10.1002/047179161X
[34] M. Hörsing, A. Ledin, R. Grabic, J. Fick, M. Tysklind, J. la Cour Jansen and H. R. Andersen, "Determination of Sorption of Seventy-Five Pharmaceuticals in Sewage Sludge," Water Research, Vol. 45, No. 15, 2011, pp. 44704482. doi:10.1016/j.watres.2011.05.033

[35] H. Sun, D. Zhu and J. Mao "Sorption of Polar and NonPolar Aromatic Compounds to Two Humic Acids with Varied Structural Heterogeniety," Environmental Toxicology and Chemistry, Vol. 27, 2008, pp. 2449-2456. doi:10.1897/08-124.1

[36] J. M. Cortés, E. Larsson and J. Å. Jönsson, "Study of the Uptake of Non-Steroid Anti-Inflammatory Drugs in Wheat and Soybean after the Application of Sewage Sludge as a Fertilizer," Science of the Total Environment, Vol. 449, 2013, pp. 385-389. doi:10.1016/j.scitotenv.2013.01.061

[37] K. M. Onesios, J. T. Yu and E. J. Bouwer, "Biodegradation and Removal of Pharmaceuticals and Personal Care Products in Treatment Systems: A Review," Biodegradation, Vol. 20, No. 4, 2009, pp. 441-466. doi:10.1007/s10532-008-9237-8

[38] J. B. Quintana, S. Weiss and T. Reemtsma, "Pathways and Metabolites of Microbial Degradation of Selected Acidic Pharmaceuticals and Their Occurrence in Municipal Wastewater Treated by a Membrane Bioreactor," Water Research, Vol. 39, No. 12, 2005, pp. 2654-2664. doi:10.1016/j.watres.2005.04.068

[39] M. Lahti and A. Oikari, "Microbial Transformation of Pharmaceuticals Naproxen, Bisoprolol and Diclofenac in Aerobic and Anaerobic Environments," Archives of Environmental Contamination and Toxicology, Vol. 61, No. 2, 2011, pp. 202-210. doi:10.1007/s00244-010-9622-2

[40] J. Leinert, K. Güdel and B. I. Escher, "Screening Method for Ecotoxicological Hazard Assessment of 42 Pharmaceuticals Considering Human Metabolism and Excretory Routes," Environmental Science and Technology, Vol. 41, No. 12, 2007, pp. 4471-4478. doi:10.1021/es0627693

[41] M. Schmitt-Jansen, P. Bartels, N. Adler and R. Altenburger, "Phytotoxicity Assessment of Diclofenac and Its Phototransformation Products," Analytical and Bioanalytical Chemistry, Vol. 387, No. 4, 2007, pp. 1389-1396. doi:10.1007/s00216-006-0825-3

[42] M. Isidori, M. Lavorgna, A. Nardelli, A. Parrella, L. Previtera and M. Rubino, "Ecotoxicity of Naproxen and Its Phototransformation Products," Science of The Total Environment, Vol. 348, No. 1-3, 2005, pp. 93-101. doi:10.1016/j.scitotenv.2004.12.068

[43] S. Peréz and D. Barceló, "First Evidence for Occurrence of Hydroxylated Human Metabolites of Diclofenac and Aceclofenac in Wastewater Using QqLIT-MS and QqTOFMS," Analytical Chemistry, Vol. 80, No. 21, 2008, pp. 8135-8145. doi: $10.1021 / \mathrm{ac} 801167 \mathrm{w}$ 